\title{
Multiple Representations' Ability in Solving Word Problem
}

\author{
Nurrahmawati, Cholis Sa'dijah, Sudirman, Makbul Muksar \\ \{nurrahmawati.1603119@students.um.ac.id ${ }^{1}$, cholis.sadijah.fmipa@um.ac.id², \\ sudirman.fmipa@um.ac.id ${ }^{3}$, makbul.muksar.fmipa@um.ac.id $\left.{ }^{4}\right\}$ \\ Universitas Negeri Malang, Indonesia ${ }^{1,2,3,4}$
}

\begin{abstract}
The purpose of this research is to explore the ability of multiple representations of college mathematics education students to solve word problems and what representation forms are used. The questions given relate to the concepts that they have learned in the previous education level. The written answer to the subject was analyzed and continued with semi-structured interviews. The results of the analysis show that there are two types of ways to solve word problems, namely the first type is to use numerical and symbolic representations, and the second type is by symbolic, numerical, and graphical representation. The difference in the students' multiple representations ability in solving problems is influenced by individual characteristics and the learning experience that they get before. Therefore, it is hoped that the teacher can use various representations in mathematics learning.
\end{abstract}

Keywords: Mathematical Multiple Representations, Problem Solving, Word Problem

\section{Introduction}

The notion about the importance of multiple representations in mathematics education has developed considerably in recent years [1]-[11]. When students have understood and studied several forms of representation about a mathematical concept, students are expected to solve problems properly. Some researchers state that multiple representational skills of students are the key to successful mathematical problem solving [7], [12], [13]. [12] states that the thinking skills of multiple representations are important skills for problem-solving, students must be able to mentally connect problem makers to solve problems correctly. Based on it, the multiple representations ability is important for students.

Multiple representation skills as the ability of students to encode appropriate information based on the domain of the given representation, choose or make representations that are appropriate for the given problem and identify the relationship between the two representations [13]. According to [14] in solving mathematical application problems, students need to observe and find specific patterns or rules in the problem. It means that students need to formulate concrete application problems into abstract mathematical problems. In the formulation process, students must have multiple representation skills to articulate the same problem in various forms or views.

The representation and multiple representation abilities are closely related to problemsolving. [14] states that representation is related to problem-solving solution strategies. [15] 
state that every problem can be solved using various types of representations and this means that there is a close relationship between problems and representations. So, students are expected to understand various forms of representation to make it easier to solve problems.

It is very important to understand the need to use various representations in mathematics learning because the use of various representations can help students in solving mathematical problems [7], [8], [11], [16], for example, mathematical problems in the form of word problems. However, problems in the form of word problems sometimes make students difficult to translate the problem [15]. For that reason, in classroom learning, the teacher's skills are needed to represent the meaning of the word problems into several forms of representation so that students can easily understand the purpose of the problem and they can solve the problem properly.

Teaching the use of various representations in mathematics learning should have been given by teachers since elementary school, in the hope that the higher the cognitive level of students, the more knowledge they have about various representations. So, when the students are already in the college, the students are expected to have the ability to use various representations in solving a problem. This is because students already have adequate experience on the use of multiple representations, both in understanding the concepts and in solving the problems. [3] revealed that multiple representations are very useful when students expand their perspective to see representational practices from topics to be tools in learning and mathematical activities. [1] stated that different representations are an important part of mathematics learning because students' ability to transfer between different representations can affect their mathematics learning achievement.

The ability of a person's multiple representations in solving problems is closely related to how a conceptual understanding of a particular concept. [17] states that the transition between and within each representation can help students developing new concepts flexibly and efficiently. Previous research shows that one indicator of conceptual understanding is the ability of a person who can structurally recognize the same relationship through various representations [18]. When students demonstrate the ability to structurally recognize the same relationships/concepts presented in different modalities (verbal, diagrammatic and symbolic), it is likely that they have developed a conceptual understanding of relationships /concepts and students' skills increased from procedural skills to structural skills [19]. [19] also states that if students can connect between multiple representations of the same concept or problem, they show conceptual understanding. Therefore, having a conceptual understanding can provide a strong basis for solving problems effectively [18].

According to [13] that how well individuals deal with different representations depends on the characteristics of students. Things that might influence are: (a) representational familiarity, the relation between the representation and the domain, understanding the format and operating the representation will be easy for learners when they are already familiar with the representation; (b) domain familiarity, the lack of experiences both in the domain or into representation used interferes their effectiveness of transferring knowledge across representation (c) a learner's age, a learner's age may also affect his/her abilities to translate between representation. One's performance represents their representation domain, and, (d) individual differences, learners' style approach of the representation that base with their need.

Several studies related to students' ability in solving mathematical problems using multiple representations, for example the results of [18] research that shows a relationship between students' achievement based on standardized tests and their ability to recognize and solve problems involving the same linear relationship structure as something unknowns are presented in different modes (symbols, diagrams, and words). The findings of the study are 
students are most successful at solving equations that are represented symbolically and are less successful in finding lengths of unknown line segments and somewhat difficult in verbal problems. The results also show that students can manipulate symbols but express a little conceptual understanding. It might be that these students particularly have little experience in using diagrams, and generally multiple representations.

The results of the research by [20] state that students have a tendency to use symbolic representation rather than other types of representation in solving the problem of two-variable linear equations. When students use verbal representations, they tend to have difficulty in composing words, while in representations of images or tables students cannot solve problems correctly. Furthermore, [14] states that in a problem formulation process, students must have multiple representation skills to articulate the same problem in various forms or views. However, some researchers show that most students fail to understand the importance of connections between different types of representations. [21] and [22] studies' state that students got difficult negotiating various forms and functions of representation.

Above research findings shows that problems in the form of symbolic representations are easier to solve by students. On the other hand, they also have a tendency in using symbolic representations in solving problems and a little difficulty using verbal representations, pictures, and tables. It inferred that the representation commonly used by students tends to be single in solving problems. This study will examine whether students can solve word problems in multiple types, whenever, it is presented in verbal representation, What type of representation used and what factors influence students using various type to solve word problems.

Every problem in mathematics sometimes has a lot of ways that can be done to solve it. Of course, in solving the problem there are also many representations that can be used. This study wants to know and explore how the multiple representation abilities of students in solving word problems, in this case, related to the material of the Two-Variable- Linear Equation System (TVLES). The reason for choosing TVLES in this research is because the questions used in TVLES allow the students to use multiple representations in finding problem-solving solutions. So, the aims of the research are exploring college students' multiple representation ability and what type of multiple representations used to solve word problems. Besides that, the researchers also to know what factors influence students' ability of multiple representations. Later, the finding becomes the basis for developing a learning that can practically improve students' multiple representation abilities.

\section{Methodology}

This study uses a qualitative approach involving first semester students in the Mathematics Education undergraduate program in Malang, East Java. The reason why choosing first semester students is because these students have just passed junior high school and senior high school level and they also have been given sufficient material related to the Two-Variable Linear Equation System (TVLES), Furthermore, the test is given to 20 students in one class with a processing time of about 60 minutes. The instrument in this study was modified from the 2013 Curriculum book as follows. 


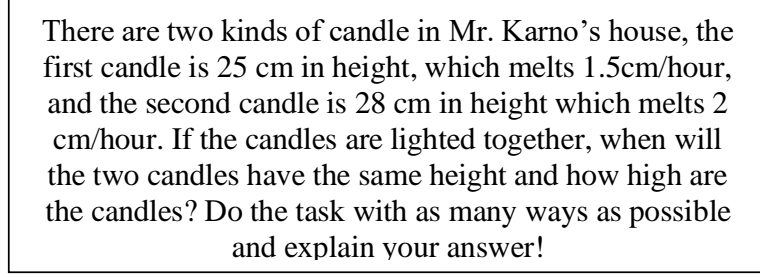

Fig. 1. Research Instrument.

Based on the instrument in figure 1, researchers asked students to give solutions to the problems in various ways. This aims to find out and explore the students' multiple representation abilities in solving these problems using a variety of possible representations because the use of different ways in solving these problems can involve various representations. Some representations that can be used to solve the problem in Figure 1 are by using numerical representations (manual method and using matrix), symbolic representation (elimination and substitution), and graphical representation (using graphics). So, the thing that wants to be seen is whether students are able to solve the problem using several ways that involve multiple representations.

After the test, the students' answers are analyzed to select the research subject. Based on the analysis by considering students' written answers, two students were chosen to be the subject of this study. The choice of subject is based on the following considerations: 1) in solving word problems, the subjects use more than one problem solving with different types of representation (at least two representations); 2) the selection of subjects is also based on responses that have the right answers and potentially provide information to structurally recognize the problem by involving various representations.

In this study, the meaning of students' multiple mathematical representations ability in solving problems refers to [23], [24], which is the ability of students to use various ways to solve problems by involving various forms of possible representations, namely by using graphical representations, symbolic representations (mathematical statements /mathematical notation, algebraic symbol); numerical representation, verbal representation (words or written text).

The next step is to conduct semi-structured interviews related to the subjects' written answers. The interview was conducted to find out and explore how the subject solved the problem by using various ways and what forms of representation used. In addition, in-depth interviews were also conducted to find out how the learning process that the subject had passed through previous levels of education. Furthermore, it will also be seen how the characteristics of the subjects related to the representational familiarity and domain familiarity. This can later be used as a basis for consideration to develop a learning or teaching material that can enhance the multiple representation abilities of students or university students.

Some examples of questions in semi-structured interviews are: "What is known and what is asked in the problem?", How many ways that you have been done? "," Why do you choose that way? ", Is there any other way to solve the problem?" For such problem which way is your teacher taught before? The results of the interview and written answers of the subjects were analyzed for further discussion and being concluded. 


\section{Result And Discussion}

\subsection{Result}

The results of this study were obtained from the answers of the subjects related to the provided instruments. From these answers it can be seen that only a few students can solve problems in various ways, most students use only one way, either by using elimination and substitution methods (symbolic representation) or by manual method (numerical representation). But there are also some students who use more than one problem-solving. Based on the consideration criteria for taking the subjects, two subjects were taken since they met the criterion. From the written answer of the subject, it appears that the subjects solved the problem by using more than one method.

SUBJECT 1 (S1)

The answer from subject 1 (S1) is that $\mathrm{S} 1$ can solve the problem in two ways, the first is by using manual method and the second is by elimination and substitution. Then the subject was interviewed to search further related to the way or other representations that the student could do. Below is the written answer of $\mathrm{S} 1$.

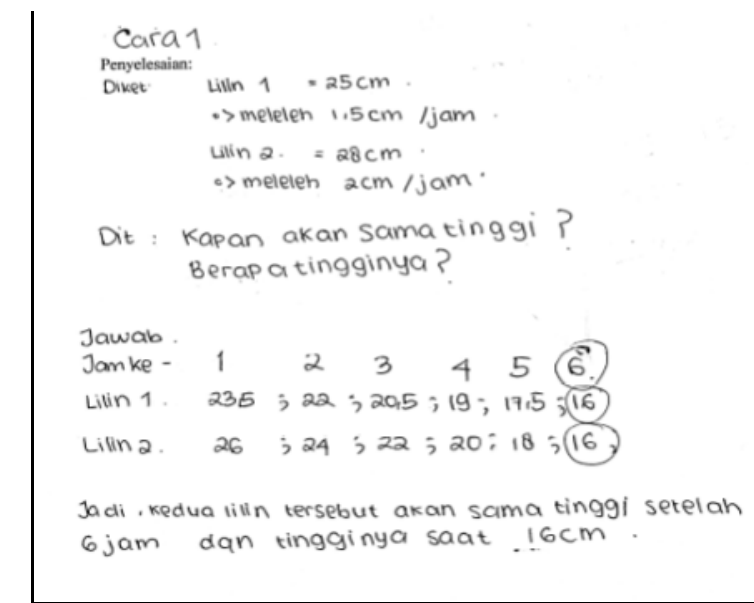

$1^{\text {st }}$ way.

It is known $\quad 1^{\text {st }}$ candle $=25 \mathrm{~cm}$

Melted in $5 \mathrm{~cm} /$ hour

$2^{\text {nd }}$ candle $=28 \mathrm{~cm}$

Melted in $2 \mathrm{~cm} /$ hour

Being asked: When were the candles at the same height?

How high are they?

Answer:

$$
\begin{array}{llccccc}
\text { Hour } & 1 & 2 & 3 & 4 & 5 & 6 \\
1^{\text {st }} \text { candle } & 23.5 ; & 22 ; & 20.5 ; & 19 ; & 17.5 ; & 16 \\
2^{\text {nd }} \text { candle } & 26 ; & 24 ; & 22 ; & 20 ; & 18 ; & 16
\end{array}
$$

So, the candles will be at the same height after 6 hours and the height is $16 \mathrm{~cm}$.

Fig. 2. First solution of S1 using numerical representation 
Based on Fig. 2, it can be seen that S1 solved word problems manually. This method involves numerical representation in its solution. Then the second method carried out by S1 to solve the word problem, presented in Fig. 3.
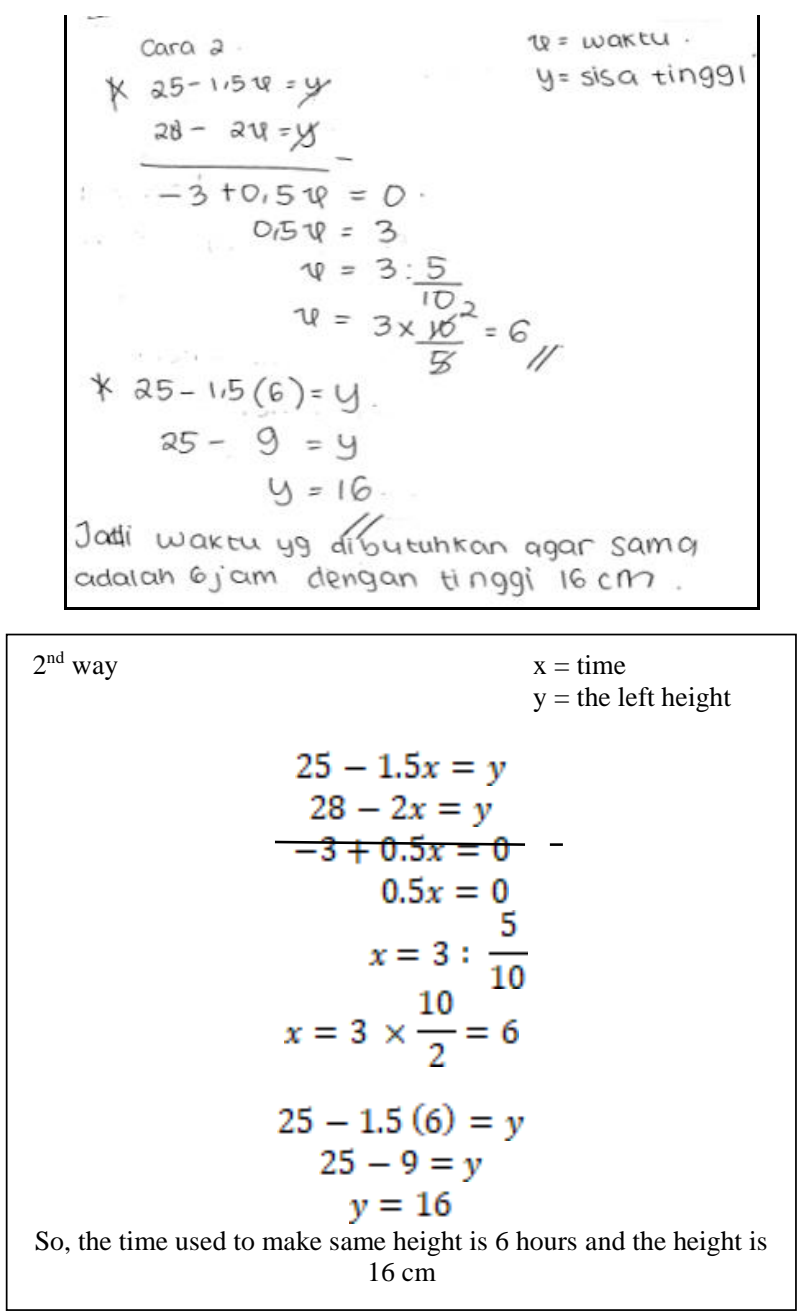

Fig. 3. Second solution of S1 using symbolic representation

In Fig. 3, viewing from the form of representation used, it can be seen that $\mathrm{S} 1$ solved word problems by using elimination and substitution. This method involves symbolic representation. Based on the written answers of S1, there are things that need to be explored more deeply about the answers that have been written. This is done to explore how the subject's mathematical problem-solving ability using various ways that can be seen from the form of representation used and whether there are other ways that can be used to solve the problem. The researcher $(\mathrm{P})$ started the interview regarding what is known in the problem and what is being asked of the question. From the results of the interview, it was seen that S1 was 
able to understand what was known and what was asked of the question. Next, the researcher asked related to the method used by S1 in completing the answers that had been written.

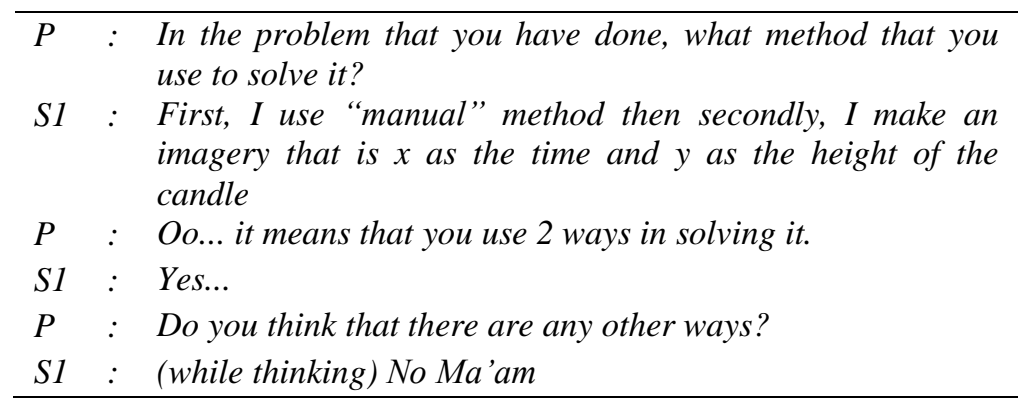

When S1 was asked whether there is another way to solve the problem or not, S1 said that under S1's knowledge there is no other way to solve the problem. When a more in-depth interview was conducted, it turned out that S1 initially only solved the problem in just one way, but after hearing a friend stated to complete the method by making an imagery, then S1 is only thought to make an imagery. S1 stated that "at first I was not thinking about making an imagery, but because I heard a friend who said, this seems to be an imagery, then I immediately thought ... yes.... if it seems to be solved by an imaginary", then S1 immediately thought of solving it by using that way and get the answer. Based on this, it can be seen that to find other ways to solve problems, S1 required a scaffold from her friend.

To S1, it was also asked whether she often see such given questions, so S1 stated that it is not always, because usually in the questions given, for the word problem is usually not many, at most it is the last number in the exam. Based on this, it can be seen that S1 is not yet familiar with problem-solving in the form of word problems, so she initially confused about what she had to do, but after being given stimuli from other people, then S1 just found out how to solve the problem by making equations.

Viewing from the step of problem-solving in a second way, S1 completed by elimination and substitution methods but S1 stated that the method used was the substitution method only. Based on this, it can be seen that S1 had not fully understood the name of the settlement method that has been done. From this, it can be seen that S1 only knows procedurally in solving the problem but has not understood the solving problem step conceptually. This is in accordance with the results of [18] study that students can manipulate symbols, but have little conceptual understanding.

Furthermore, the results of the interview revealed that the preferred method of S1 in solving the problem was by manual method (Figure 2) and when she was asked how the teacher taught when she was in junior high school or senior high school, the results of the interview were below.

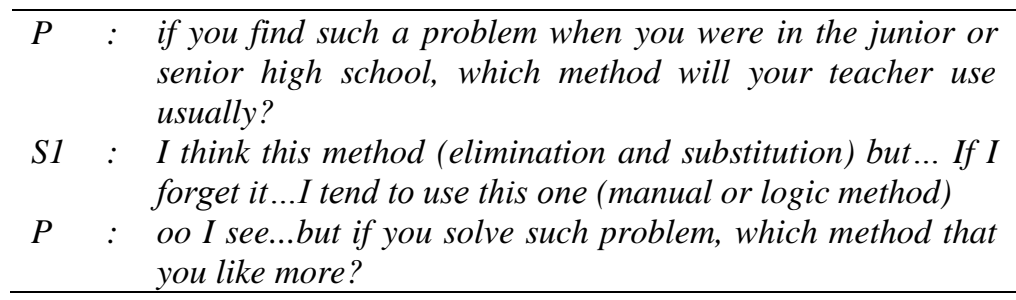




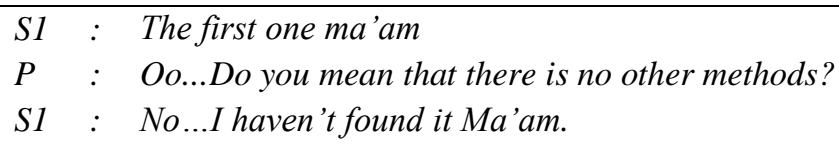

Furthermore, the researcher asked S1 about what concepts are discussed in the problem, then S1's answers are below.

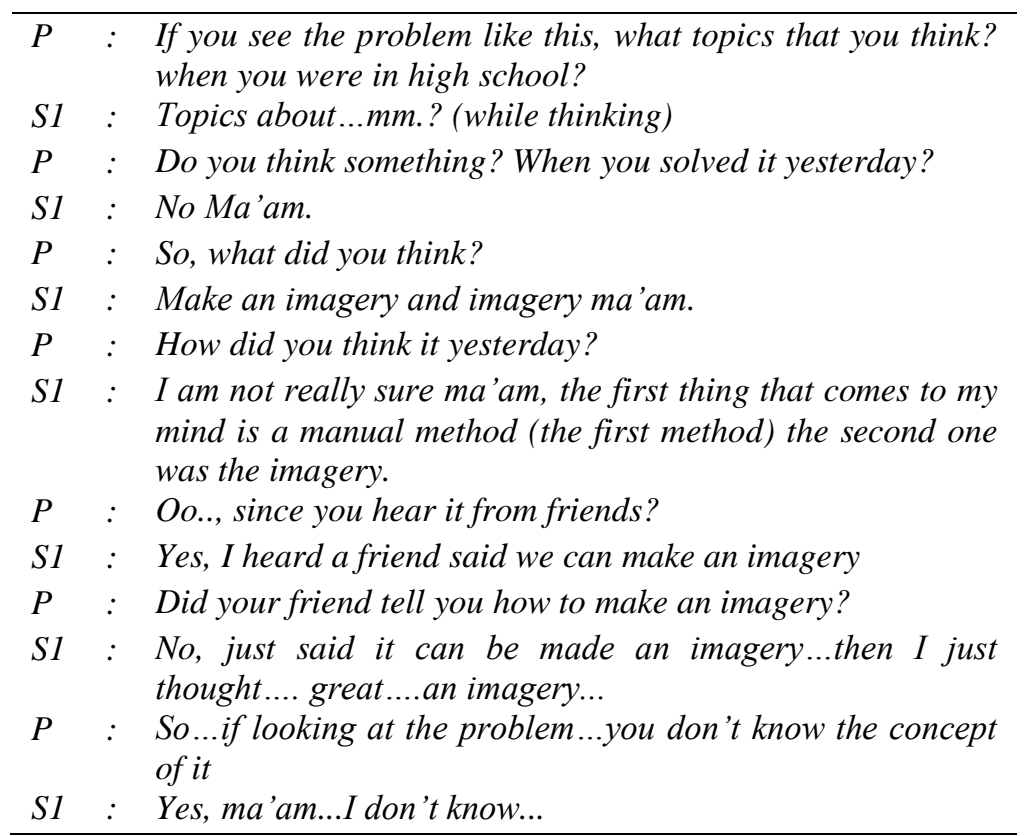

Based on the interview it can be seen that the S1 does not understand what the concept of the problem given and if there is not much knowledge about the forms of representation in the students' mind, the representation that will be raised is also limited.

SUBJECT 2 (S2)

Judging from the answers of subject 2 (S2) that S2 can also solve the problem using two methods, the first method used substitution method and the second method, S2 named it to trial and error method. The written answer of $\mathrm{S} 2$ is presented below. 


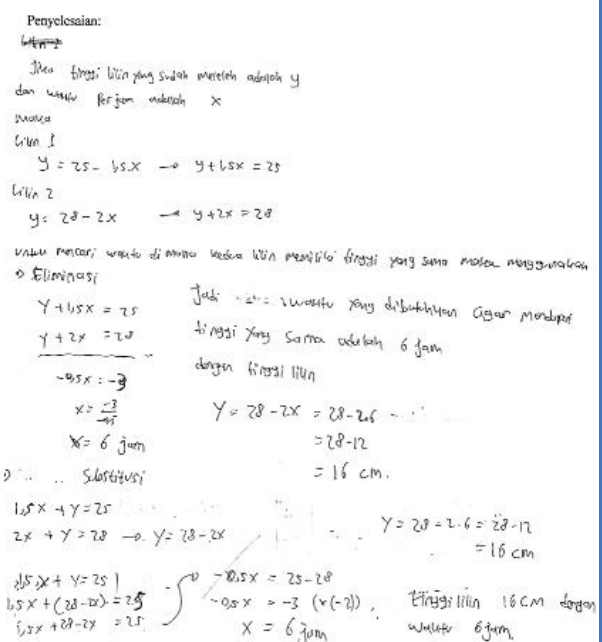

To find out when do the two candles have the same height, so the way used is

$\star$ Elimination

$$
\begin{gathered}
y+1.5 x=25 \\
y+2 x=28 \\
-0.5 x=-3 \\
\hline x=\frac{-9}{-0.5} \\
y+1.5 x=25 \\
x=6 \text { hours }
\end{gathered}
$$

So, the time used to be at the same height is 6 hours and the height is

$$
\begin{gathered}
y=28-2 x=28-2.6 \\
=28-12 \\
\hline
\end{gathered}
$$

$\star$ Substitution

$$
1.5 x+y=25
$$$$
2 x+y=28
$$$$
1.5 x+y=25
$$$$
1.5 x+(28-2 x)=25
$$$$
1.5 x+28-2 x=25
$$$$
-0.5 x=25-28
$$$$
-0.5 x=-3
$$$$
x=6 \text { hours }
$$

$$
\begin{array}{rlr}
y & =28-2.6 & \text { The candle height is } 16 \mathrm{~cm} \mathrm{in} \\
& =28-12 & 6 \text { hours } \\
& =16 \mathrm{~cm} &
\end{array}
$$

Fig. 4. First method solution of S2 using symbolic representation 
Based on Fig. 4, it can be seen that the first way used by S2 to solve word problems is by elimination and substitution. In this way, the representation used is symbolic representation. Very clearly the steps of S2 in solving the problem. Furthermore, the second method carried out by $\mathrm{S} 2$ in solving problems can be seen in Fig. 5 below.

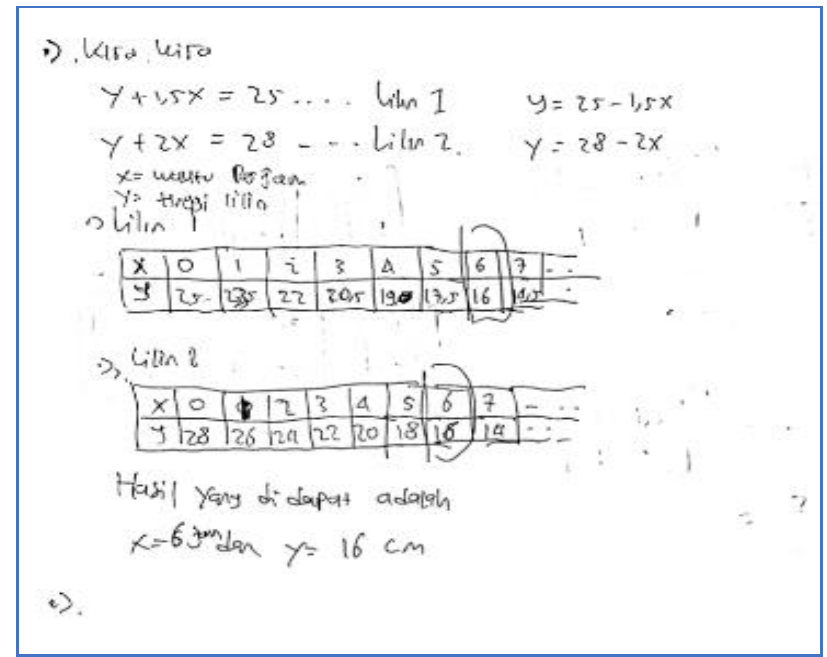

\begin{tabular}{|c|c|c|c|c|c|c|c|c|c|}
\hline \multicolumn{6}{|c|}{$\begin{array}{l}\text { - By prediction } \\
\qquad \begin{array}{l}y+1.5 x=25 \ldots \ldots .1^{\text {st }} \text { candle } \\
y+2=28 \ldots \ldots . .2^{\text {nd }} \text { candle }\end{array}\end{array}$} & \multicolumn{4}{|c|}{$\begin{array}{l}y=25-1.5 x \\
y=28-2 x\end{array}$} \\
\hline \multicolumn{10}{|c|}{$\begin{array}{l}x=\text { time/hour } \\
\quad y=\text { the candle height }\end{array}$} \\
\hline $\mathrm{x}$ & 0 & 1 & 2 & 3 & 4 & 5 & 6 & 7 & $\ldots$ \\
\hline $\mathrm{y}$ & 25 & 23.5 & 22 & 20.5 & 19 & 17.5 & 16 & 14.5 & $\ldots$ \\
\hline \multicolumn{10}{|c|}{$2^{\text {nd }}$ candle } \\
\hline $\mathrm{x}$ & 0 & 1 & 2 & 3 & 4 & 5 & 6 & 7 & $\ldots$ \\
\hline $\mathrm{y}$ & 28 & 26 & 24 & 22 & 20 & 18 & 16 & 14 & $\ldots$ \\
\hline $\begin{array}{l}\text { The } \\
\mathrm{x}=\end{array}$ & & & & & & & & & \\
\hline
\end{tabular}

Fig. 5. Second solution of $\mathrm{S} 2$ using numerical representation.

Figure 5 shows that the second method used by S2 in solving word problem is by trial and error, and the representation used is numerical representation.

Based on the answers of S2 which are presented in Figures 4 and 5, it can be seen that S2 solves the problem given using two forms of representation, the first is using symbolic forms and the second is using numerical forms. From the written answer, S2 also shows that there are other ways used to solve the problem, but the answer is not continued and deleted. Therefore, to explore more about the ability of multiple representations of S2 in solving word 
problems, the researcher conducted in-depth interviews. The first question was whether S2 understands what was known about the question and what was being asked of the question, so based on the interview it can be seen that S2 understands the purpose of the problem and understands what was known and asked about the question. Next, the researcher asked S2 as follows.

\begin{tabular}{|c|c|c|}
\hline$P$ & : & $\begin{array}{l}\text { You got a word problem yesterday, didn't it... then ... what } \\
\text { is asked by the problem? }\end{array}$ \\
\hline$S 2$ & : & $\begin{array}{l}\text { I think the main point is the ways used to get the exact } \\
\text { time when the candles are at the same height... it just } \\
\text { the ways how to solve it... }\end{array}$ \\
\hline$P$ & : & Then... what ways that you used to solve it...? \\
\hline$S 2$ & : & $\begin{array}{l}\text { The first way by elimination and substitution... and the } \\
\text { second way by trial and error }\end{array}$ \\
\hline$P$ & $:$ & $\begin{array}{l}\text { Do you think that there are only two ways to solve it or } \\
\text { any other ways? }\end{array}$ \\
\hline$S 2$ & : & There are some other ways. \\
\hline
\end{tabular}

Surprisingly, S2 replied that there were other ways to solve it, so the researcher resumed the interview.

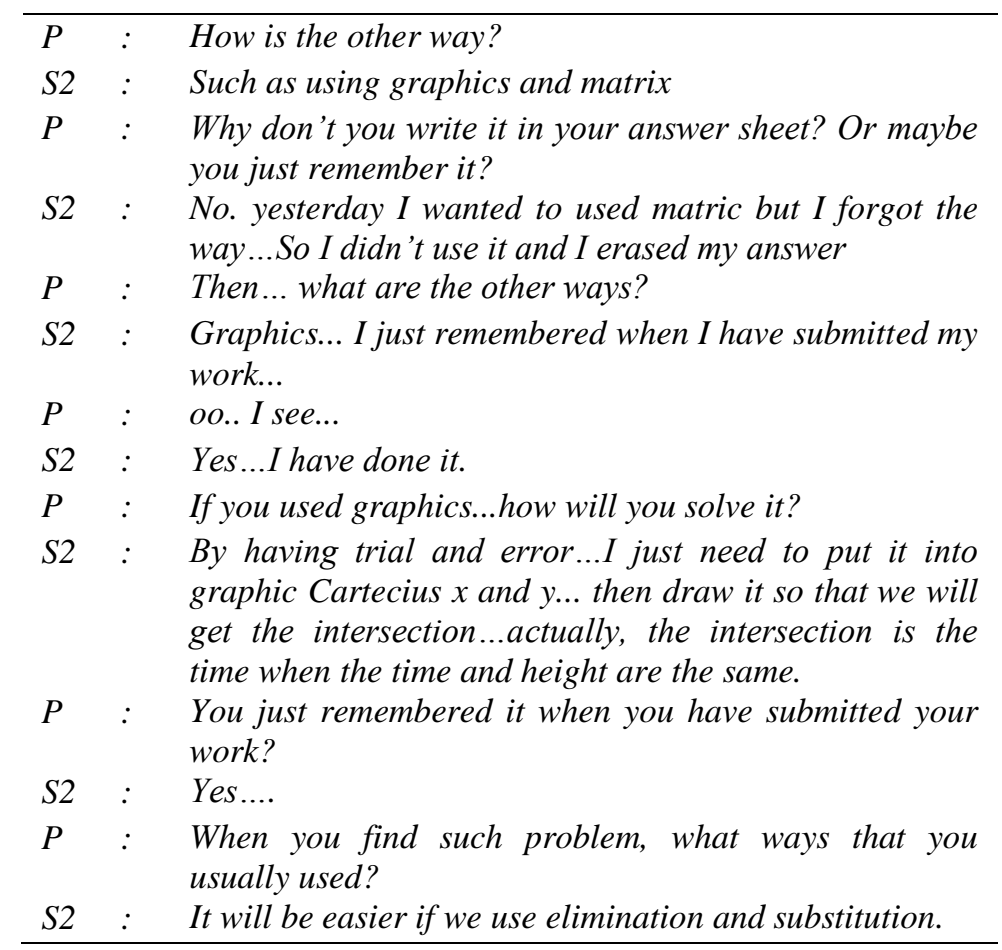

Based on these interviews, it is surprising that $\mathrm{S} 2$ knows several ways to solve problems by using several methods, namely elimination and substitution (symbolic representation), trial and error (numerical representation), graphs (graphical representations), and with matrices 
(numerical representations). However, only two methods are written, using substitution and elimination and using trial and error. For the graph, S2 just realized the way when the task has just been collected. Whereas for using matrices, there are steps to solve these problems that have not been understood by S2.

When being asked which method will be used if the same problem was asked, S2 replied, " I will solve the problem using the elimination method" when being asked why to use the method, then S2 answered, "because I understand better to eliminate it first, then substitute it ... and I think using substitution is more complicated, and if I use the matrix ... sometimes I forget the steps ... if I use trial and error it's too long, and the graphics are too long, so I prefer to use this one (elimination and substitution). Based on this, it can be seen that $\mathrm{S} 2$ comprehend more about how to solve the problems, so she is knowing which method is more effective and appropriate to use. This study supports [18] statement that the more diverse representational knowledge of students, the more likely they are to be able to produce the right solution for the problem and the exposure of various representations helps students in developing their mathematical knowledge. Furthermore, [25] stated that students' understanding of mathematical concepts is reflected in the number of representations used to solve problems.

Based on the interview results that have been given by S2, it seems that S2 seems to have become accustomed to or familiar with problems with characteristics of such those questions. After being asked, it was true that $\mathrm{S} 2$ was accustomed to discussing such questions, because when she was in high school, S2 often joined Olympiad. Furthermore, the researcher also interviewed how $\mathrm{S} 2$ was taught how to solve if the problem was like a problem in this research instrument. The results of the interview are as follows.

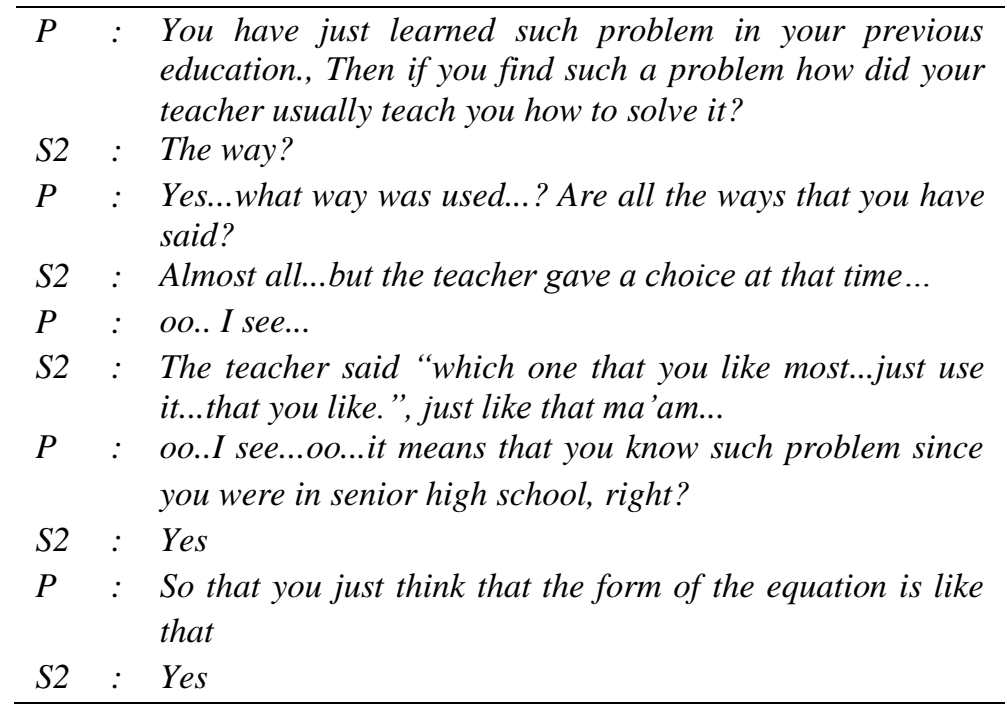

When being asked what is the concept of the given problem, it can be seen in the following interview.

\begin{tabular}{l}
\hline$P: \begin{array}{l}\text { What concepts that you know if you are given such a } \\
\text { problem? }\end{array}$ \\
S2 : It's ...what...two variables ...two variables equation ma'am...
\end{tabular}




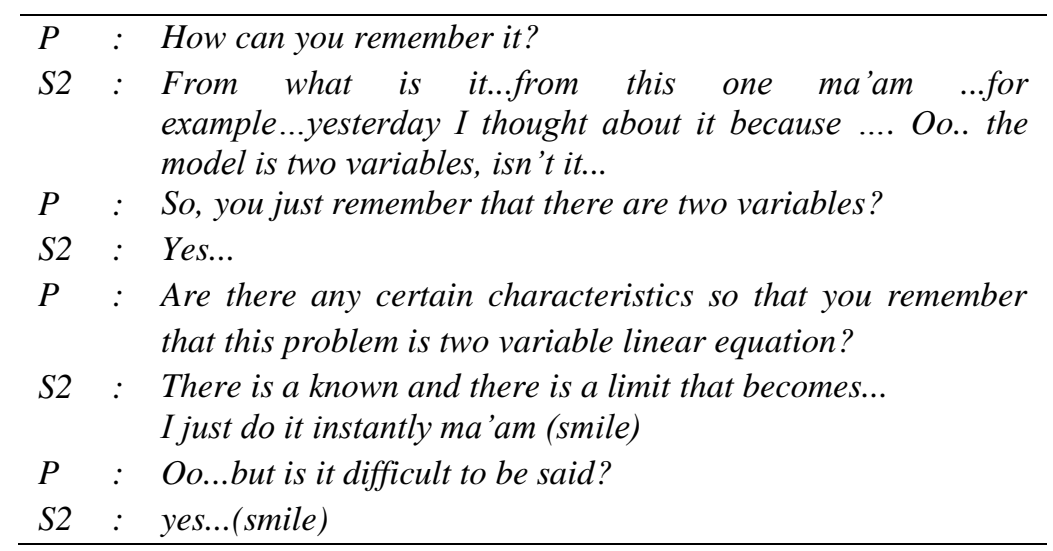

Based on the result of the interview, it seems that S2 has a conceptual understanding about TVLES.

\subsection{Discussion}

The results of interviews with S1 and S2 were also asked about the subjects' learning experience in the secondary education about how the teacher taught if there were a problem as in this study. S1 answered that the teacher usually taught by making equations first and then completing it by elimination and substitution. Based on this, it can be seen that $\mathrm{S} 1$ is only taught in one way, namely elimination and substitution, whereas there are several other ways that can be done to solve this problem. While S2 said that when she was in high school the teacher taught it in several ways, but which way that the students choose depends on the student him/herself. Therefore, the way teachers teach influence more on the multiple representation's abilities of students.

When the teacher teaches in many ways or many representations, the student will have knowledge of various representations in his/her thinking, so that when solving a problem, students will be able to choose which representation is appropriate to be used to solve a word problem. This is in line to [16] opinion that it makes sense to assume that the development of conception and the ability of students to use representations are influenced by the conception of the representation of their teacher.

Furthermore, based on written answers of S1 and S2 as well as in-depth interviews, the first answers written by students (the first written answers) are the preferred way for students to solve the word problem. S1 preferred to solve the problem by using the manual method, but S1 will also try first by elimination and substitution but she did not find the answer, S1 will complete it manually, S1 did not analyze which method should be used to solve the problem. While S2 preferred to solve the word problem by elimination and substitution because this method is easier to understand and more efficient in working on it, while the graph and matrix methods take longer to complete. Based on this, S2 has had sufficient understanding of multiple representations, because according to [26] some characteristics of the theory of understanding multiple representations is that one is able to determine the exact representation used in a particular problem, the next characteristic is that one can identify strengths and weaknesses, differences and similarities in various concepts of representations.

Based on it, it can be concluded that S2 has a good understanding related to the concept of Two-Variable Linear Equation System (TVLES) so that S2 has the ability to have multiple 
representations in understanding concepts and solving problems involving multiple representations. S2 knows how to solve in several ways, namely by elimination and substitution, by trial and error, by matrix, and by drawing graphs, but only two ways are written, namely by using symbolic and numerical representations, because the method is understood by S2. [23] stated that the ability to be able to move multiple representations from the same concept can be seen as an indication of conceptual understanding and also a goal in learning. While S1 has the ability to use multiple representations in solving problems, the concept of TVLES needs to be improved.

The broad representation of a concept is also influenced in solving word problems involving various representations. In addition, how the subject's experience in previous learning also influenced the ability of multiple subject representations, namely whether there are many ways of solving or many representations taught by the teacher in understanding the concept or in solving problems. Furthermore, students' ability to connect between mathematical concepts also influences their multiple representation abilities in solving problems. This is consistent with the opinion of [13] that several factors that influence a person to make different representations are the representation familiarity and domain familiarity.

Comprehension related to mathematical concepts also influences the use of various representations. As stated by [20] that the ability to understand concepts and the relationship between mathematical concepts is found to be a necessary condition for achieving the ability of multi-mathematical representation. Therefore, it is recommended that teachers use different types of representations, such as verbal, tables and pictures, to improve students' comprehension of the material.

A learning design that can improve the ability of multiple representations of students in solving problems is needed. The result of the study [27] stated that it is better for teachers to use different learning strategies so that students can do various representations in the classroom so that they can improve learning performance. Therefore, the learning done by the teacher should be able to use various representations, one of which is the material of the TwoVariable Linear Equation System, because when the child already has these abilities, students will be able to solve a mathematical problem easily.

\section{Conclusion}

There are two types of solutions that students make. The first type is that students solve problems using numerical representations and symbolic representations, while the second type is solving word problems using symbolic, numerical, and graphic representations.

College students' multiple representations ability in solving mathematical problems depends on the characteristics of students, namely familiarity with the concept of TVLES and familiarity with the given representation. Furthermore, this ability is also influenced by how teachers teach TVLES concepts in the previous education level. Based on this, it is important for teachers to design a learning environment that enhances the students' multiple representations ability so that the students can understand a concept deeply and can solve a problem properly.

Recommendations based on this research are (1) the teacher should introduce the use of multiple representations in understanding a concept and be able to connect a concept with other concepts by involving several representations; (2) The information that must be learned 
in class must be consistently and explicitly presented to students in various ways so that they can develop various methods and thinking techniques because it will improve their cognitive

\section{References}

[1] Y. H. Lin, M. Wilson, and C. L. Cheng, "An investigation of the nature of the influences of item stem and option representation on student responses to a mathematics test," Eur. J. Psychol. Educ., vol. 28, no. 4, pp. 1141-1161, 2013.

[2] M. Durkaya, E. Ö. Şenel, M. F. Öçal, A. Kaplan, Z. Aksu, and A. C. Konyaloglu, "Pre-service mathematics teachers' multiple representation competencies about determinant concept," in Procedia - Social and Behavioral Sciences, 2011, vol. 15, pp. 2554-2558.

[3] D. A. Stylianou, “11. an examination of student.PDF," Educ Stud Math, vol. 76, pp. 265-280, 2011.

[4] J. Cai, "U.S. and Chinese Teachers' Constructing, Knowing, and Evaluating Representations to Teach Mathematics," Math. Think. Learn., vol. 7, no. 2, pp. 135-169, 2009.

[5] M. A. Rau, "Conditions for the Effectiveness of Multiple Visual Representations in Enhancing STEM Learning,” Educ. Psychol. Rev., vol. 29, no. 4, pp. 717-761, 2017.

[6] P. N. Tripathi, "Developing Mathematical Understanding through Multiple Representations," Math. Teach. Middle Sch., vol. 13, no. 8, pp. 438-445, 2008.

[7] W. Y. Hwang, N. S. Chen, J. J. Dung, and Y. L. Yang, "Multiple representation skills and creativity effects on mathematical problem solving using a multimedia whiteboard system," Educ. Technol. Soc., vol. 10, no. 2, pp. 191-212, 2007.

[8] A. P. Bal, "The Examination of Representations used by Classroom Teacher Candidates in Solving Mathematical Problems," Educ. Sci. Theory Pract., vol. 14, no. 6, pp. 2349-2365, 2014.

[9] A. Dreher, S. Kuntze, and S. Lerman, "Why Use Multiple Representations in the Mathematics Classroom? Views of English and German Preservice Teachers," Int. J. Sci. Math. Educ., vol. 14, pp. 363-382, 2016.

[10] G. Goldin and N. Shteingold, "Systems of Representations and the Development of Mathematical Concepts. In A.A. Cuoco, \& F.R. Curcio (Eds.)," in The Role of Representation in School Mathematics, Reston: NCTM Publication, 2001, pp. 1-24.

[11] NCTM, "Principle and Standards for School Mathematics," Reston, Va, 2000.

[12] C. Blake and E. Scanlon, "Reconsidering simulations in science education at a distance: Features of effective use," J. Comput. Assist. Learn, vol. 23, pp. 491-502, 2007.

[13] S. Ainsworth, "DeFT: A conceptual framework for considering learning with multiple representations," Learn. Instr., vol. 16, no. 3, pp. 183-198, 2006.

[14] S. E. Ainswroth, "Designing Effective multirepresentational Learning Environments," ESRC Cent. Res. Dev. Instr. Train. Univ. Nottingham, vol. technical, p. 47, 1999.

[15] A. Gagatsis and I. Elia, "the Effects of Different Modes of Representation on Mathematical Problem Solving,” Proc. 28th Conf. Int. Gr. Psychol. Math. Educ., vol. 2, pp. 447-454, 2004.

[16] D. A. Stylianou, "Teachers' conceptions of representation in middle school mathematics," J. Math. Teach. Educ., vol. 13, no. 4, pp. 325-343, 2010.

[17] D. J. Within and P. Whitin, "Within.pdf," Teach. Child. Math., vol. 18, no. 8, pp. 490-496, 2012.

[18] S. A. Ihedioha, "Students' A bility and Achievement in Recognizing Multiple Representations in Algebra," Asian J. Educ. e-Learning, vol. 2, no. 1, pp. 89-97, 2014.

[19] R. M. Panasuk and M. L. Beyranevand, "Algebra Students' Ability to Recognize Multiple Representations and Achievement," Int. J. Math. Teach. Learn., 2010.

[20] Nizaruddin, Muhtarom, and Y. H. Murtianto, "EXPLORING OF MULTI MATHEMATICAL REPRESENTATION CAPABILITY IN PROBLEM SOLVING ON SENIOR HIGH,” Probl. Educ. 21 Century, vol. 75, no. 6, pp. 591-598, 2017.

[21] A. A. Nistal, W. van Dooren, G. Clarebout, J. Elen, and L. Verschaffel, "Conceptualising, investigating and stimulating representational flexibility in mathematical problem solving and learning: A critical review,” ZDM - Int. J. Math. Educ., vol. 41, no. 5, pp. 627-636, 2009. 
[22] A. Heinze, J. R. Star, and L. Verschaffel, "Flexible and adaptive use of strategies and representations in mathematics education," ZDM - Int. J. Math. Educ., vol. 41, no. 5, pp. 535-540, 2009.

[23] R. Lesh, T. Post, and M. Behr, "Lesh et al 1987 Representations and Translations," 1987. .

[24] S. M. Matteson, "Mathematical literacy and standardized mathematical assessments," Read. Psychol., vol. 27, no. 2-3, pp. 205-233, 2006.

[25] M. E. Brenner et al., "Learning by Understanding: The Role of Multiple Representations in Learning Algebra,” Am. Educ. Res. J., vol. 34, no. 4, pp. 663-689, 1997.

[26] K. D. Owens and M. A. (Ken. Clements, "Representations in spatial problem solving in the classroom,” J. Math. Behav., vol. 17, no. 2, pp. 197-218, 1998.

[27] J. Cai and S. Hwang, "Generalized and generative thinking in US and Chinese students , mathematical problem solving and problem posing," J. Math. Behav., vol. 21, pp. 401-421, 2002. 